\title{
BMJ Open Cross-sectional and prospective associations of neighbourhood environmental attributes with screen time in Japanese middle-aged and older adults
}

\author{
Yung Liao, ${ }^{1,2}$ Ai Shibata, ${ }^{3}$ Kaori Ishii, ${ }^{2}$ Mohammad Javad Koohsari, ${ }^{2,4,5}$ \\ Koichiro Oka ${ }^{2}$
}

To cite: Liao Y, Shibata A, Ishii $\mathrm{K}$, et al. Cross-sectional and prospective associations of neighbourhood environmental attributes with screen time in Japanese middle-aged and older adults. BMJ Open 2018;8:e019608. doi:10.1136/ bmjopen-2017-019608

- Prepublication history for this paper is available online. To view these files, please visit the journal online (http://dx.doi. org/10.1136/bmjopen-2017019608).

Received 15 September 2017 Revised 28 December 2017 Accepted 5 January 2018
Check for updates

${ }^{1}$ Department of Health Promotion and Health Education, National Taiwan Normal University, Taipei, Taiwan

${ }^{2}$ Faculty of Sport Sciences, Waseda University, Saitama, Japan

${ }^{3}$ Faculty of Health and Sport Sciences, University of Tsukuba, Tsukuba, Japan

${ }^{4}$ Institute for Health and Ageing, Australian Catholic University,

Melbourne, Australia

${ }^{5}$ Behavioural Epidemiology

Laboratory, Baker IDI Heart and

Diabetes Institute, Melbourne,

Australia

Correspondence to

Dr Yung Liao;

liaoyung@ntnu.edu.tw

\section{ABSTRACT}

Objectives This study examined cross-sectional and 2-year prospective associations of perceived and objectively measured environmental attributes with screen time among middle-aged Japanese adults.

Design Prospective cohort study.

Setting Nerima and Kanuma cities of Japan.

Participants Data were collected from adults aged 40-69 years living in two cities of Japan in 2011 (baseline: $\mathrm{n}=1011 ; 55.3 \pm 8.4$ years) and again in 2013 (follow-up: $n=533 ; 52.7 \%$ of baseline sample).

Measures The exposure variables were five geographic information system-based and perceived attributes of neighbourhood environments (residential density, access to shops and public transport, footpaths, street connectivity), respectively. The outcome variables were baseline screen time (television viewing time and leisure-time internet use) and its change over 2 years. Multilevel generalised linear modelling was used.

Results On average, participants' screen time was not statistically different over 2 years (2.3 hours/day at baseline and 2.2 hours/day at follow-up; $P=0.24$ ). There were cross-sectional associations of objective $(\exp (\beta)$ : $1.11 ; 95 \% \mathrm{Cl} 1.01$ to 1.22$)$ and perceived $(1.12 ; 1.02$ to 1.23 ) good access to public transport, perceived good access to shop $(1.18 ; 1.04$ to 1.36$)$ and perceived good street connectivity $(1.11 ; 1.01$ to 1.23$)$ with higher time spent in screen time at baseline. No objective and perceived environmental attributes were significantly associated with change in screen time.

Conclusions Activity-supportive neighbourhood environmental attributes appear to be related to higher levels of screen time cross-sectionally. Pattern of screen time might be maintained rather than changed over time under the same neighbourhood environments. Environmental interventions that promote physical activity may need to consider the potential negative health impact of screen time in Japan.

\section{INTRODUCTION}

Sedentary behaviour, defined as any waking behaviour characterised by an energy

\section{Strengths and limitations of this study}

- This study used both cross-sectional and prospective design to provide more confirmative evidence on this issue.

- This study used both subjectively and objectively measured environmental measures, which could better understand what specific conditions of built environment people actually live in, and how people perceive and realise these specific environmental attributes could influence their time spent in screen time.

- The outcome variable, self-reported screen time, may be subject to recall bias.

- Potential confounders such as self-selection of neighbourhoods and home environment were not examined in this study.

- The final sample may not be representative of the populations of Nerima and Kanuma cities.

expenditure $\leq 1.5$ metabolic equivalents while in a sitting or reclining posture, has been recognised a novel risk factor for health. ${ }^{1}$ Literature has shown the deleterious associations between sitting time and all-cause mortality, cardiovascular disease, type 2 diabetes, overweight/obesity, specific types of cancer and mental health, independent of physical activity. ${ }^{23}$ In particular, among several domains of sedentary behaviour, screenbased sedentary behaviour is highly prevalent and increasing rapidly among adults, partly because of easily available media-related technologies. ${ }^{4}$ Research has reported screen time (television (TV) viewing and leisuretime internet use) is associated with negative health outcomes ${ }^{5-7}$ and has been found to be a predominant component of leisure-time sedentary behaviour in adults. ${ }^{8} 9$ Therefore, with the increasing engagement in screen 
time, ${ }^{4}{ }^{10}$ there is an urgent need to develop effective strategies to reduce screen time to prevent diseases and obesity.

From the ecological perspective, it is crucial to better understand environmental determinants of screen time to develop population-based interventions for a longterm impact. ${ }^{11}$ However, previous studies examining associations between built environmental attributes and screen-based sedentary behaviour are limited in several significant ways. Most of these previous studies were of cross-sectional design, ${ }^{12-14}$ reporting from Australia ${ }^{1215}$ and the USA, ${ }^{13}{ }^{14}$ as well as focusing more on only TV viewing and objectively measured walkability. ${ }^{12} 1315$ These previous studies have reported that lowly walkable neighbourhood environment is associated with higher TV viewing time, ${ }^{12} 1415$ whereas one study has found no associations. ${ }^{13}$ However, it remains unclear what specific conditions of built environment people actually live in and how people perceive and realise these specific environmental attributes could influence their time spent in screen time. Thus, in order to strengthen the basis of evidence for developing environmental interventions, further studies examining the longitudinal relationship between specific built perceived and objectively measured neighbourhood environmental attributes and screen time in adults are needed. In particular, limited studies have focused on Asian countries, and it is crucial to further examine how both perceived and objectively measured environmental attributes are related to changes in screen time in different density, cultural and environmental contexts. These findings would be important to inform policy makers and intervention designers for developing strategies to reduce the increase in screen time through environmental approaches. Therefore, the present study examined cross-sectional and 2-year prospective associations of objective and perceived environmental attributes with screen time in middle-aged Japanese adults.

\section{MATERIALS AND METHODS \\ Participants}

The present study is a prospective cohort study with two waves of data collection: baseline in 2011 and follow-up in 2013. This study used data from a part of the Healthy Built Environment in Japan project. At baseline, a total of 3000 residents aged 40-69 years and living in two cities in Japan (Nerima City, part of the Tokyo metropolitan area with 716124 residents and an area of $48 \mathrm{~km}^{2}$; Kanuma City, a regional city with 102348 residents and an area of $491 \mathrm{~km}^{2}$ ) were randomly selected from the registry of residential addresses based on gender, age group and residential city. The baseline survey was completed by 1076 residents (response rate: $35.9 \%$ ). Excluding the missing data, the final sample was 1011 for the cross-sectional analyses. After 2 years, 533 (52.7\% of the baseline respondents) completed the follow-up survey.

\section{Outcome variables}

Participants reported their time spent in TV viewing and leisure-time internet use over a usual week (screen time). Participants were asked: 'On how many days did you do the activity during leisure time in the past 7 days?' and 'On average, how many minutes did you do the activity during leisure time on the days that you did it?' Using this format, we identified time spent sitting in screen time by multiplying the number of days participants watched TV and used internet during leisure time by the average amount of time spent doing so per day. The scale was previously shown to have reasonable reliability and validity. ${ }^{16}$ The test-retest reliability of the items was moderate (range 0.6-0.8), and the validity, defined as correlations with 3-day behavioural log data, was also moderate (range $0.3-0.6) .{ }^{17}$ For cross-sectional associations, the outcome variable was baseline screen time per day. For prospective associations, the outcome variable was change of screen time per week from baseline to follow-up survey.

\section{Exposure variables}

The exposure variables of this study were five environmental attributes-population density, sidewalk availability, access to public transportation, access to destinations and street connectivity-measured both subjectively and objectively at baseline. These domains were selected on the basis of walkability components and other environmental attributes from previous reviews. ${ }^{18} 19$ The perceived measures were identified using the Japanese version of the International Physical Activity Questionnaire Environmental Module (IPAQ-E) with a 4-point Likert scale (strongly agree, somewhat agree, somewhat disagree and strongly disagree). The scale has been shown to have good reliability. ${ }^{20}$ Five items of IPAQ-E were included: (1) population density ('What is the main type of housing in your neighborhood?' For this question, the five options were detached single-family housing; apartments with 2-3 storeys; mix of single-family housing and apartments with 2-3 storeys; condos with 4-12 storeys; and condos with $>13$ storeys); (2) sidewalk availability ('There are sidewalks on most of the streets in my neighbourhood'); (3) access to public transportation ('It is less than a 10-15 min walk to a transit station from my home'); (4) access to destinations ('There are many places to go within easy walking distance of my home'); and (5) street connectivity ('There are many 4-way intersections in my neighbourhood'). Population density was divided into 'lower (detached single-family housing)' and 'higher (others)'. Other four perceived environmental attributes were categorised into 'agree' (strongly agree and somewhat agree) and 'disagree' (somewhat disagree and strongly disagree).

Objective environmental attributes were measured using geographic information systems (GIS). The following five measures were calculated for each participant within an $800 \mathrm{~m}$ radius buffer of their residential address (this buffer area corresponded to a neighbourhood setting, which was also used to obtain participants' perceptions): (1) population density (the number of 
population per square kilometre); (2) sidewalk availability (the length of roads with sidewalks $(\mathrm{m})$ per square kilometre); (3) access to public transportation (the total number of train stations and bus stops per square kilometre); (4) access to destinations (the total number of 30 destination types including convenience store, supermarket, hardware shop, fruit store, dry cleaning store, coin laundry, clothing store, post office, library, book store, fast food store, café, bank, restaurant, video shop, video rental shop, pharmacy, drug store, the hairdresser's, park, gym, fitness club, sports facility, kindergarten, elementary school, junior high school, high school, 2-year college, 4-year college and university based on a previous study and IPAQ-E ${ }^{20}{ }^{21}$ ); and (5) street connectivity (the total number of intersections per square kilometre). These five objectively measured environmental attributes were dichotomised using the median.

\section{Covariates}

The selection of covariates was based on previous studies. ${ }^{22}{ }^{23}$ Data on respondents' gender (men, women), age (40-49, 50-59 or 60-69 years), current marital status (married, unmarried), educational level (less than 13 years, 13 years or more), employment status (full-time employment, not full-time employment), household income (less than 5 million yen, or 5 million yen or more), body mass index (less than $25 \mathrm{~kg} / \mathrm{m}^{2}, 25 \mathrm{~kg} / \mathrm{m}^{2}$ and higher), residential area (Nerima City and Kanuma City), physical function, and moderate-to-vigorous physical activity (MVPA) were included. Physical function was measured by the Japanese version of the Medical Outcomes Study Short Form 8-Item Health Survey. ${ }^{24}$ Participants were asked: 'During the past 4 weeks, how much did physical health problems limit your physical activities (such as walking or climbing stairs)?' MVPA was measured by the self-administered, short Japanese version of the International Physical Activity Questionnaire (IPAQ-SV). The test-retest reliability $(\mathrm{r}=0.72-0.93)$ and criterion validity $(\mathrm{r}=0.39)$ of the version of the IPAQ-SV are good and acceptable, respectively. ${ }^{25}$ The total number of minutes per week in vigorous-intensity physical activity, moderate-intensity physical activity and walking was computed.

\section{Statistical analyses}

For cross-sectional associations, generalised linear modelling (GLM), specifying a gamma distribution and a $\log$ link, was used to examine cross-sectional associations of perceived and objectively measured environmental attributes with screen time at baseline because the distribution of outcome variable was skewed. The covariates were adjusted for baseline demographic variables including gender, age, marital status, education attainment, household income, working status and MVPA. For prospective associations, GLM was also used to identify the relationships of perceived and objectively measured environmental attributes at baseline with follow-up screen time over 2 years, adjusted for sociodemographic variables at baseline, screen time at baseline and employment status change. This approach is equivalent to modelling change in screen time and controls for regression to the mean, which has been used in a previous study. ${ }^{15}$ Residence area was used as the area level unit of all analysis. Results of each model are reported as antilogarithms of the regression coefficients (and their respective 95\% CI). The expected proportional increase (for values $>1$ ) or decrease (for values $<1$ ) in screen time for 'environmental conditions that would support physical activity' environment (reference: 'not support' category) was calculated. For cross-sectional analysis, coefficients less than 1 denote proportionally less time spent in screen time (eg, $\exp (\beta)=0.95$ means $5 \%$ less time), whereas coefficients more than 1 denote proportionally more time spent in screen time, relative to the reference category $($ eg, $\exp (\beta)=1.06$ means $6 \%$ more time). For prospective analysis, coefficients less than 1 denote proportionally decreased time spent in screen time, whereas coefficients more than 1 denote proportionally increased time spent in screen time, relative to the reference category. Statistical analyses were conducted using STATA V.13; the level of significance was set at $\mathrm{P}<0.05$.

\section{RESULTS}

Basic characteristics of the baseline sample $(n=1011$, mean age: $55.8 \pm 4.3$ years) and follow-up sample $(\mathrm{n}=553$, mean age: $54.6 \pm 8.3$ years) are presented in table 1 . On average, participants' screen time was not statistically different over 2 years (2.3 hours/day at baseline and 2.2 hours/day at follow-up; $\mathrm{P}=0.24)$. Table 2 shows that at baseline, after adjusting for potential confounders (model 2), cross-sectional associations of objectively measured $(\exp (\beta): 1.11$; $95 \%$ CI 1.01 to 1.22$)$ and perceived $(\exp (\beta): 1.12 ; 95 \%$ CI 1.02 to 1.23$)$ good access to public transport, perceived $\operatorname{good}$ access to shop $(\exp (\beta): 1.18 ; 95 \%$ CI 1.04 to 1.36$)$ and perceived good street connectivity $(\exp (\beta): 1.11$; $95 \%$ CI 1.01 to 1.23 ) with higher time spent in screen time were found. As table 3 shows, for the prospective associations, no objectively measured and perceived environmental attributes were significantly associated with change in screen time.

\section{DISCUSSION}

To our knowledge, this is the first study to examine cross-sectional and prospective associations between neighbourhood environments and screen time using both perceived and objective measures of specific neighbourhood environmental attributes among middle-aged Japanese adults in an Asian country. The results of this study support previous findings that built environmental attributes of neighbourhoods that are related to physical activity may also play an important role in influencing sedentary behaviours independently, ${ }^{12} 141526$ and further extend the results showing that both perceived (good access to public transport, access to shop and street 
Table 1 Characteristics of baseline and follow-up respondents

\begin{tabular}{lll}
\hline & $\begin{array}{l}\text { Sample for } \\
\text { cross-sectional } \\
\text { analyses } \\
\text { (n=1011) }\end{array}$ & $\begin{array}{l}\text { Sample for } \\
\text { prospective } \\
\text { analyses } \\
\text { (n=533) }\end{array}$ \\
\hline $\begin{array}{l}\text { Baseline } \\
\text { Gender, \% men }\end{array}$ & $512(51.2)$ & $276(51.8)$ \\
\hline $\begin{array}{l}\text { Age, mean (SD) } \\
\text { Marital status, \% }\end{array}$ & $55.8(4.3)$ & $54.6(8.3)$ \\
married & $844(84.3)$ & $454(85.2)$ \\
\hline $\begin{array}{l}\text { Educational } \\
\text { attainment, \% with } \\
\text { tertiary education }\end{array}$ & $536(53.6)$ & $308(57.8)$ \\
\hline $\begin{array}{l}\text { Household income (yen), \% } \\
\text { <5 000 000 p.a. }\end{array}$ & $492(49.2)$ & $244(45.8)$ \\
\hline $\begin{array}{l}5 \text { 000 000 p.a.+ } \\
\text { Refused to answer or } \\
\text { missing }\end{array}$ & $494(49.4)$ & $283(53.1)$ \\
\hline $\begin{array}{l}\text { Work status, \% non- } \\
\text { working }\end{array}$ & $743(74.2)$ & $6(1.1)$ \\
\hline $\begin{array}{l}\text { BMl, mean (SD) } \\
\text { MVPA (hour/week), } \\
\text { mean (SD) }\end{array}$ & $23(3.2)$ & $406(76.2)$ \\
\hline $\begin{array}{l}\text { Screen time (hour/ } \\
\text { day), mean (SD) }\end{array}$ & $2.3(1.9)$ & $22.9(3.3)$ \\
\hline Fow & $9.2(12.4)$ \\
\hline
\end{tabular}

Follow-up

\begin{tabular}{lll}
$\begin{array}{l}\text { Change in working } \\
\text { status }\end{array}$ & - & \\
\hline Keep working & - & $388(72.8)$ \\
\hline Start working & - & $17(3.2)$ \\
\hline Stop working & - & $18(3.4)$ \\
$\quad$ Not working & - & $110(20.6)$ \\
\hline $\begin{array}{l}\text { Screen time (hour/day), } \\
\text { mean (SD) }\end{array}$ & - & $2.2(1.7)$ \\
\hline
\end{tabular}

BMI, body mass index; MVPA, moderate-to-vigorous physical activity; p.a, per annum.

connectivity) and objectively measured (good access to public transport) physical activity-supportive environmental attributes are related to higher levels of screen time cross-sectionally. These findings would be important to inform policy makers and intervention designers that when designing environmental approach to promote physical activity, it would be crucial to consider the negative impact of screen time, at least in Japan.

Contrary to expectations, a neighbourhood environment with GIS-measured good access to public transportation, and perceived good access to destinations, good access to public transportation and good street connectivity, was positively associated with higher levels of screen time in adults, which have been found to be positively related to higher levels of physical activity. ${ }^{1827}$ The present results were also inconsistent with previous studies from
Western countries that have reported inverse associations between high walkable environment and screen-based sedentary time. ${ }^{121415}$ Only one Belgium study reported similar results with the present study that high walkable environment is positively associated with total sitting time. ${ }^{26}$ The possible speculation for these results could be that physical activity-supportive neighbourhood environment (eg, there are so many shops, train stations and bus stops within $1.6 \mathrm{~km}$ radius of their house) could reduce the time spent in commute and daily errand, and thus adults may have more leisure time to engage in screen time. Although there is limited evidence in existing literature to draw the conclusion and the possible mechanism regarding the inverse associations between environment and screen time, the present study may have several important implications. First of all, the perceptions of environmental attributes should be considered as predictors of screen time in future studies. The present results indicate that perceived environmental attributes might be better predictors of screen time than objective ones. How middle-to-older-aged adults perceive and understand their neighbourhood environment might be important in their decision to spend time in screen time in their home. Moreover, further studies in Asian countries using specific environmental measures are needed due to differences in residential density, culture and built environment between Western and Asian countries. Finally, examining the relationships among environmental factors, physical activity and sedentary behaviour concurrently would be a priority to better understand the potential positive or negative health effects of environment on both physical activity and sedentary behaviours to inform policy initiatives.

Another novel finding is that there were no prospective associations between screen time and objective and perceived environmental attributes over 2 years. The possible explanation for this result could be that the follow-up duration of this study was only 2 years and screen time is a highly domestic behaviour for adults during leisure time, which may be maintained for years unless there is adjustment in home environment or change in employment status. Therefore, the present study might provide a preliminary understanding on built environmental determinants of screen time for developing effective population-based interventions. ${ }^{10}{ }^{11}$ Therefore, to further confirm the prospective associations, studies with a longer follow-up time are needed in the future.

This study has several limitations. First, the outcome variable-self-reported screen time-may be subject to recall bias. Thus, future studies should consider measuring screen time using objective measures to provide more confirmative evidence. Second, the use of the IPAQ-SV may have overestimated the time spent in MVPA. Third, potential confounders such as self-selection of neighbourhoods and home environment were not examined in this study. Finally, the participants who responded to the follow-up survey were more likely to have higher educational levels $(58.1 \%$ vs $47.4 \%, \mathrm{P}=0.002)$ and have 
Table 2 Proportional change $(95 \% \mathrm{Cl})$ in screen time according to objective and perceived environmental attributes at baseline $(n=1011)$

\begin{tabular}{|c|c|c|c|c|c|c|}
\hline & \multicolumn{3}{|c|}{ Model 1} & \multicolumn{3}{|c|}{ Model 2} \\
\hline & $\operatorname{Exp}(\beta)$ & $95 \% \mathrm{Cl}$ & $P$ value & $\operatorname{Exp}(\beta)$ & $95 \% \mathrm{Cl}$ & $P$ value \\
\hline \multicolumn{7}{|l|}{ Perceived } \\
\hline Residential density (high) & 1.02 & 0.91 to 1.14 & 0.69 & 1.02 & 0.93 to 1.13 & 0.66 \\
\hline Access to destination (good) & 1.10 & 0.99 to 1.22 & 0.06 & 1.12 & 1.02 to 1.23 & $0.02^{*}$ \\
\hline Access to public transportation (good) & 1.20 & 1.03 to 1.39 & $0.01^{*}$ & 1.18 & 1.04 to 1.36 & $0.01^{*}$ \\
\hline Sidewalk (yes) & 1.04 & 0.94 to 1.15 & 0.43 & 1.06 & 0.97 to 1.17 & 0.20 \\
\hline Street connectivity (good) & 1.10 & 0.99 to 1.23 & 0.08 & 1.11 & 1.01 to $1.23^{*}$ & $0.04^{*}$ \\
\hline \multicolumn{7}{|l|}{ GIS } \\
\hline Residential density (high) & 0.96 & 0.87 to 1.06 & 0.45 & 0.96 & 0.87 to 1.06 & 0.44 \\
\hline Access to destination (good) & 1.07 & 0.96 to 1.18 & 0.21 & 1.05 & 0.96 to 1.16 & 0.29 \\
\hline Access to public transportation (good) & 1.13 & 1.03 to 1.25 & $0.01^{*}$ & 1.11 & 1.01 to 1.22 & $0.03^{*}$ \\
\hline Sidewalk (yes) & 0.99 & 0.89 to 1.10 & 0.88 & 0.99 & 0.91 to 1.10 & 0.98 \\
\hline Street connectivity (good) & 0.97 & 0.88 to 1.08 & 0.60 & 1.00 & 0.91 to 1.11 & 0.95 \\
\hline
\end{tabular}

Generalised linear model (specifying a gamma distribution and using a log link).

Model 1: unadjusted model; model 2: adjusted for gender, age, marital status, education attainment, household income, employment status, car ownership status, BMI, physical function and MVPA at baseline.

Results of each model are reported as antilogarithms of the regression coefficients (and their respective $95 \% \mathrm{Cl}$ ). Coefficients less than 1 denote proportionally less time spent in screen time, whereas coefficients more than 1 denote proportionally more time spent in screen time, relative to the reference category.

${ }^{*} \mathrm{P}<0.05$.

BMI, body mass index; GIS, geographic information system; MVPA, moderate-to-vigorous physical activity.

Table 3 Proportional change $(95 \% \mathrm{Cl})$ in screen time over 2 years according to objective and perceived environmental attributes, after adjusting for baseline leisure-time sitting for transport $(n=533)$

\begin{tabular}{|c|c|c|c|c|c|c|}
\hline & \multicolumn{3}{|c|}{ Model 1} & \multicolumn{3}{|c|}{ Model 2} \\
\hline & $\operatorname{Exp}(\beta)$ & $95 \% \mathrm{Cl}$ & $P$ value & $\operatorname{Exp}(\beta)$ & $95 \% \mathrm{Cl}$ & $P$ value \\
\hline \multicolumn{7}{|l|}{ Perceived } \\
\hline Residential density (high) & 1.06 & 1.16 to 1.25 & 0.37 & 1.11 & 0.97 to 1.27 & 0.14 \\
\hline Access to destination (good) & 0.96 & 0.84 to 1.10 & 0.54 & 1.00 & 0.88 to 1.14 & 0.97 \\
\hline Access to public transportation (good) & 1.06 & 0.87 to 1.29 & 0.54 & 1.08 & 0.89 to 1.30 & 0.46 \\
\hline Sidewalk (yes) & 0.96 & 0.84 to 1.09 & 0.50 & 0.99 & 0.87 to 1.12 & 0.84 \\
\hline Street connectivity (good) & 1.03 & 0.89 to 1.19 & 0.72 & 1.06 & 0.92 to 1.22 & 0.39 \\
\hline \multicolumn{7}{|l|}{ GIS } \\
\hline Residential density (high) & 1.01 & 0.88 to 1.14 & 0.94 & 1.05 & 0.92 to 1.20 & 0.47 \\
\hline Access to destination (good) & 1.06 & 0.93 to 1.20 & 0.41 & 1.07 & 0.94 to 1.23 & 0.29 \\
\hline Access to public transportation (good) & 1.02 & 0.90 to 1.16 & 0.78 & 1.02 & 0.90 to 1.16 & 0.74 \\
\hline Sidewalk (yes) & 1.10 & 0.97 to 1.24 & 0.16 & 1.11 & 0.98 to 1.26 & 0.10 \\
\hline Street connectivity (good) & 1.04 & 0.91 to 1.18 & 0.58 & 1.08 & 0.94 to 1.24 & 0.26 \\
\hline
\end{tabular}

Generalised linear model (specifying a gamma distribution and using a log link).

Model 1: unadjusted model; model 2: adjusted for gender, age, marital status, education attainment, household income, BMI, physical function and MVPA at baseline, change in employment status and car ownership.

Results of each model are reported as antilogarithms of the regression coefficients (and their respective $95 \% \mathrm{Cl}$ ). Coefficients less than 1 denote proportionally decreased time spent in screen time, whereas coefficients more than 1 denote proportionally increased time spent in screen time, relative to the reference category.

${ }^{*} \mathrm{P}<0.05$.

BMI, body mass index; GIS, geographic information system; MVPA, moderate-to-vigorous physical activity. 
higher income $(53.4 \%$ vs $43.9 \%, \mathrm{P}=0.01)$ than those who did not. Thus, the final sample may not be representative of the populations of Nerima City and Kanuma City. The strengths of this study were its cross-sectional and prospective design and the utilisation of five subjectively and objectively measured environmental components, which could provide more confirmative evidence on this issue.

\section{CONCLUSION}

Activity-supportive neighbourhood environmental attributes appear to be related to higher levels of screen time cross-sectionally. Patterns of screen time might be maintained rather than changed over time under the same neighbourhood environments. Environmental interventions that promote physical activity may need to consider the potential negative health impact of screen time in Japan.

Contributors Study concept and design: KO, AS, KI. Acquisition, analysis or interpretation of data: YL, AS. Drafting of the manuscript: YL, AS, MJK. Critical revision of the manuscript for important intellectual content: KO, AS, KS, KI. Statistical analysis: YL, AS. Administrative, technical or material support: KI, MJK. Study supervision: KO, AS.

Funding This study was supported by the Grant-in-Aid for Scientific Research (no 26242070) from Japan Society for the Promotion of Science and the 29th Research Grant in Medical and Health Science of Meiji Yasuda Life Foundation of Health and Welfare.

Competing interests None declared.

Patient consent Not required.

Ethics approval Written informed consent was obtained from all respondents. This survey received prior approval from the Institutional Ethics Committee of Waseda University (2010-238).

Provenance and peer review Not commissioned; externally peer reviewed.

Data sharing statement This study used data from a part of the Healthy Built Environment in Japan (HEBEJ) project. Data and material are available in the Lab of Behavioral Sciences (KO), College of Sport Sciences at Waseda University (address: 2-579-15 Mikajima Tokorozawa, Saitama 359-1192, Japan).

Open Access This is an Open Access article distributed in accordance with the Creative Commons Attribution Non Commercial (CC BY-NC 4.0) license, which permits others to distribute, remix, adapt, build upon this work non-commercially, and license their derivative works on different terms, provided the original work is properly cited and the use is non-commercial. See: http://creativecommons.org/ licenses/by-nc/4.0/

(c) Article author(s) (or their employer(s) unless otherwise stated in the text of the article) 2018. All rights reserved. No commercial use is permitted unless otherwise expressly granted.

\section{REFERENCES}

1. Owen N, Salmon J, Koohsari MJ, et al. Sedentary behaviour and health: mapping environmental and social contexts to underpin chronic disease prevention. Br J Sports Med 2014;48:174-7.

2. Thorp AA, Owen N, Neuhaus M, et al. Sedentary behaviors and subsequent health outcomes in adults a systematic review of longitudinal studies, 1996-2011. Am J Prev Med 2011;41:207-15.
3. Teychenne M, Ball K, Salmon J. Sedentary behavior and depression among adults: a review. Int J Behav Med 2010;17:246-54.

4. Institute for Information and Communications Policy. Survey of communication media use and behavior. 2014 http://www.soumu.go. jp/main_content/000357570.pdf (cited 2016 Jul 4).

5. Grøntved A, Hu FB, Fb H. Television viewing and risk of type 2 diabetes, cardiovascular disease, and all-cause mortality: a metaanalysis. JAMA 2011;305:2448-55.

6. Matthews CE, Chen KY, Freedson PS, et al. Amount of time spent in sedentary behaviors in the United States, 2003-2004. Am J Epidemiol 2008;167:875-81.

7. Vandelanotte $C$, Sugiyama T, Gardiner P, et al. Associations of leisure-time internet and computer use with overweight and obesity, physical activity and sedentary behaviors: cross-sectional study. $J$ Med Internet Res 2009;11:e28.

8. Owen N, Leslie E, Salmon J, et al. Environmental determinants of physical activity and sedentary behavior. Exerc Sport Sci Rev 2000;28:153-8

9. Sugiyama T, Healy GN, Dunstan DW, et al. Is television viewing time a marker of a broader pattern of sedentary behavior? Ann Behav Med 2008;35:245-50.

10. Owen N, Sugiyama T, Eakin EE, et al. Adults' sedentary behavior determinants and interventions. Am J Prev Med 2011;41:189-96.

11. Owen N. Sedentary behavior: understanding and influencing adults' prolonged sitting time. Prev Med 2012;55:535-9.

12. Sugiyama T, Salmon J, Dunstan DW, et al. Neighborhood walkability and TV viewing time among Australian adults. Am J Prev Med 2007;33:444-9.

13. Coogan PF, White LF, Evans SR, et al. The influence of neighborhood socioeconomic status and walkability on TV viewing time. J Phys Act Health 2012:9:1074-9.

14. Kozo J, Sallis JF, Conway TL, et al. Sedentary behaviors of adults in relation to neighborhood walkability and income. Health Psychol 2012;31:704-13.

15. Ding D, Sugiyama T, Winkler E, et al. Correlates of change in adults' television viewing time: a four-year follow-up study. Med Sci Sports Exerc 2012;44:1287-92.

16. Salmon J, Owen N, Crawford D, et al. Physical activity and sedentary behavior: a population-based study of barriers, enjoyment, and preference. Health Psychol 2003;22:178-88.

17. Ishii K, Shibata A, Oka K. Sociodemographic and anthropometric factors associated with screen-based sedentary behavior among Japanese adults: a population-based cross-sectional study. $J$ Epidemiol 2013;23:382-8.

18. Brownson RC, Hoehner CM, Day K, et al. Measuring the built environment for physical activity: state of the science. Am J Prev Med 2009;36:S99-123.

19. Saelens BE, Sallis JF, Frank LD. Environmental correlates of walking and cycling: findings from the transportation, urban design, and planning literatures. Ann Behav Med 2003;25:80-91.

20. Inoue S, Murase N, Shimomitsu T, et al. Association of physical activity and neighborhood environment among Japanese adults. Prev Med 2009;48:321-5.

21. Hanibuchi T, Kawachi I, Nakaya T, et al. Neighborhood built environment and physical activity of Japanese older adults: results from the Aichi Gerontological Evaluation Study (AGES). BMC Public Health 2011;11:657.

22. Ding D, Sugiyama T, Winkler E, et al. Correlates of change in adults television viewing time: a four-year follow-up study. Med Sci Sports Exerc 2012;44:1287-92.

23. Shibata A, Oka K, Sugiyama T, et al. Perceived neighbourhood environmental attributes and prospective changes in TV viewing time among older Australian adults. Int J Behav Nutr Phys Act 2015;12:50.

24. Fukuhara S, Suzukamo Y. Manual of the SF- 8 Japanese edition. Kyoto: Institute for Health Outcomes \& Process Evaluation Research, 2004. (in Japanese).

25. Murase N, Katsumura T, Ueda C, et al. International Standardization of Physical Activity Level: Reliability and Validity Study of the Japanese Version of the International Physical Activity Questionnaire (IPAQ) (Kosei no Shihyo). J Health Welfare Statistics 2003;49:1-9. (in Japanese).

26. Van Dyck D, Cardon G, Deforche B, et al. Neighborhood walkability and sedentary time in Belgian adults. Am J Prev Med 2010;39:25-32.

27. Saelens BE, Handy SL. Built environment correlates of walking: a review. Med Sci Sports Exerc 2008;40:S550-S566. 